\title{
Um mapa para além das fronteiras: aprender e ensinar história nos anos finais da escolarização básica
}

A map beyond the borders: learning and teaching history in the final years of elementary schooling

Jean Carlos Moreno*

\section{Freitas, Itamar}

Aprender e ensinar história nos anos finais da escolarização básica Aracaju: Criação, 2014. 200p. ${ }^{1}$

Existem bons manuais de introdução ao ensino de História disponíveis no mercado editorial brasileiro. Em geral, essas publicações tratam de questões curriculares e metodológicas destinadas à formação básica dos aspirantes à docência. Em primeiro momento, o título, Aprender e ensinar história nos anos finais da escolarização básica, passa a impressão de se tratar de mais um manual dedicado ao ensino disciplinarizado de História, especialmente à fase atendida por professores especialistas dentro do sistema educacional brasileiro. Contudo, os interlocutores diretos do livro de Itamar Freitas não são, na verdade, os iniciantes, mas os formadores de professores, esses profissionais híbridos, pesquisadores e docentes das fronteiras entre a História e a Educação, em geral lotados nas cadeiras de Didática, Metodologia ou Prática de Ensino dos cursos de Licenciatura em História.

Diante da profusão de pesquisas e publicações das últimas duas décadas, a área de ensino de História já comportaria pelo menos uma dezena de subespecialidades. Mas a maioria dos profissionais, pesquisadores e professores da área resiste, mantendo o olhar abrangente, necessário à formação do licenciando, ainda que sob a suspeição de muitos de seus pares acadêmicos cada vez mais especializados em temáticas ou períodos específicos. É diante dessa resistência que o livro de Freitas abraça a difícil tarefa de construir um balanço das principais questões em torno do Ensino de História.

\footnotetext{
* Universidade Estadual do Norte do Paraná (Uenp). jeanmoreno09@gmail.com
} 
Conjugando a formação de historiador com uma sólida trajetória na história da escolarização e das ideias pedagógicas, Freitas organiza e enuncia, com precisão, os problemas que envolvem o ensinar e aprender História em sete capítulos nos quais explora múltiplas fontes - documentos oficiais, currículos, programas, livros didáticos - apresentando uma síntese agregadora ao final de cada um. Já no primeiro capítulo, "As Finalidades da Disciplina Escolar História no Brasil Republicano (1900-2011)”, retoma a questão da intencionalidade do ensino de História e do papel formador do conhecimento histórico para o desenvolvimento de jovens e adolescentes. Nesse, como em todos os demais capítulos, há um pano de fundo que é a relutância dos historiadores de profissão em assumir a discussão do uso público do conhecimento que produzem. Passando por filósofos, historiadores, autores de livros didáticos e, principalmente, por programas de ensino oriundos de reformas curriculares, o capítulo explicita as diversas funções atribuídas à formação histórica escolar ao longo do tempo, desde construir a nacionalidade, pensar historicamente, preparar para a participação política, formar consciências, até contribuir para o desenvolvimento de atitudes de tolerância. A definição das finalidades, para o autor, é fruto de um jogo político em disputa, como projeto, por toda a sociedade e pelos interessados mais imediatos do processo de escolarização pais, alunos, professores, gestores e professores da licenciatura.

Já no $2^{\circ}$ capítulo, “Aprendizagens Históricas no Brasil Recente: contribuições da Espanha, Inglaterra e Alemanha (1980-2011)", aprofundam-se as questões em torno do significado da aprendizagem histórica e seus processos. Mapeando as correntes de pesquisa, o autor acaba por caracterizar dois grupos - não homogêneos - de concepções sobre a aprendizagem histórica. O primeiro que, genericamente, pode ser chamado de construtivista, é legatário do trabalho da psicologia, especialmente de Piaget e Vygotsky. Nele, o autor situa os trabalhos baseados em Carretero, Pozo, Asencio, Bruner e Ausubel. O segundo grupo utiliza como base para a aprendizagem a própria epistemologia da História. É o caso da Educação Histórica de Peter Lee e da Didática da História de Jörn Rüsen. Analista atento, Freitas enfatiza a diferença de concepção de aprendizagem entre os dois últimos, um enfocando o processo de aquisição da compreensão sobre o trabalho do historiador, e o outro, o pensar historicamente nas suas dimensões éticas e estéticas. 
Os "Conceitos Históricos" são a temática do $3^{\circ}$ capítulo. Grande parte do trabalho se dá em inventariar as diversas concepções sobre o que é um conceito e como ele surge. Para isto, mobiliza-se a psicologia cognitiva, a linguística de Saussure, os tipos ideais weberianos e a epistemologia da história, com destaque para Veyne e Koselleck. Outra parte do capítulo se propõe a analisar os conteúdos conceituais no ensino de História, investigando manuais de fundamentos e metodologias e uma coleção didática destinada à segunda fase do Ensino Fundamental que se propõe explicitamente a trabalhar com os conceitos históricos. Nessa parte, destaca-se a nomenclatura utilizada por Hilary Cooper e Peter Lee, diferenciando os conceitos substantivos e os conceitos meta-históricos. $\mathrm{O}$ autor conclui ressaltando que, para a maioria dos pesquisadores do ensino de História, os conceitos têm papel central na aprendizagem histórica, como mediadores da interpretação do real, ressalvando que estes devem ser acompanhados dos conteúdos procedimentais, das atitudes e dos valores.

É justamente a discussão sobre o que são os conteúdos históricos o objeto do $4^{\circ}$ capítulo. Aqui, como em outros capítulos, Freitas presta um grande serviço ao ensino de História ao "desnaturalizar" a ideia de conteúdo, não a confundindo com a informação histórica. Como historiador da escolarização, retoma a constatação de Chervel entendendo por conteúdo tudo aquilo que se ensina em uma disciplina. Definição esta que abarca muito mais processos, por vezes inconscientes, do que o simples repassar de informações. O autor ressalta, no entanto, que os conteúdos explícitos são debitários das finalidades atribuídas às disciplinas. Após uma breve discussão sobre o entendimento a respeito dos conteúdos históricos nos programas de estudos sociais norte-americanos, na Educação Histórica, na Didática da História e nos PCNs, levantam-se alguns exemplos de como, recentemente, vários países - Austrália, Brasil, Canadá, Estados Unidos, Inglaterra, México, Nova Zelândia, Portugal e Suíça - têm entendido essa questão. Conclui-se que, na maioria dos casos, predomina o par conhecimentos (no sentido de conceitos, mas também entendido como "substância a ser consumida, reconhecida, recuperada, utilizada") e habilidades (uma ação que deve ser adquirida ou desenvolvida pelo aluno).

No $5^{\circ}$ capítulo, "Currículos nacionais para o ensino de história (19312009)", o autor inquire os sentidos e a organização proposta para a disciplina (ou matéria, em um caso) História nas grandes reformas educacionais 
nacionais, identificadas pelo nome dos seus gestores: Francisco Campos (1931), Gustavo Capanema (1942/1951), Jarbas Passarinho (1971) e Paulo Renato Souza (1996/2001). A ênfase incide na organização de currículos com a perspectiva integrada ou intercalada, conforme o contexto com maior ou menor dose de nacionalismo. Embora também comentadas, sente-se alguma falta de abordagem maior sobre as reformas curriculares dos anos 1980 que ajudariam, até mesmo, a entender melhor a ebulição em torno dos PCNs. Única reforma ampla feita em ambiente de democracia política, a proposta educacional dos anos 1990 produziu documentos distintos, inclusive quanto à perspectiva do ensino de História. Esta é mais uma constatação importante feita pelo autor. Segundo ele, os PCNs de História para o Ensino Fundamental, por exemplo, significaram um esforço de aproximar a perspectiva dos novos problemas, objetos e abordagens anunciados pelos pesquisadores franceses com a ênfase na experiência coletiva, herdada do marxismo. Atento aos movimentos do presente, diante da rejeição aos PCNs e da ausência de currículos de história sistêmicos em nível nacional, Freitas aponta a probabilidade de as expectativas de aprendizagem ou dos itens de avaliação das provas do ENEM tornarem-se base para a elaboração dos programas do ensino de História.

Nos dois últimos capítulos, o livro põe literalmente o "dedo na ferida" do Ensino de História tratando de dois aspectos, salvo louváveis incursões, pouco explorados pela pesquisa e mesmo pelas prescrições curriculares: a progressão e a avaliação. O sexto capítulo trata da progressão dos conteúdos históricos em currículos nacionais de países da América (Argentina e Chile), Europa (França e Inglaterra) e Ásia (Índia e Tailândia), entre 1995 e 2012. Novamente a psicologia cognitiva, a Educação Histórica e a Didática da História são abordadas no mapeamento teórico referente à progressão da aprendizagem em História. $\mathrm{Na}$ análise dos currículos dos países são constatadas algumas tentativas de estabelecer progressão em relação às habilidades interpretativas. No que tange aos conteúdos substantivos, a ausência de discussão é quase regra geral. O apelo do autor resume a situação drástica: “os alunos 'amadurecem', sob o ponto de vista físico, cognitivo e afetivo. Por essa razão, não podemos manter as mesmas estratégias de ensino e, principalmente, os mesmos 'trabalhos de aluno’ e conteúdos históricos por anos a fio” (p.148-149). Urge, portanto, pesquisa e discussão sobre as possibilidades de progressão das aprendizagens históricas no Ensino Básico. 
O último capítulo dedica-se à avaliação no ensino de História analisando os dispositivos nacionais e estaduais brasileiros entre 1996 e 2012. Após incursão nas teorias sobre avaliação da aprendizagem, especialmente o comportamentalismo e o cognitivismo, o autor mapeia a legislação e as reformas curriculares estaduais recentes, percebendo que predominam as prescrições genéricas sobre o modelo - formativa e diagnóstica -, o objeto e as técnicas de avaliação. A discussão sobre a especificidade do avaliar em História é praticamente ausente.

Embora o livro não traga uma conclusão geral, não é difícil perceber que as concepções de aprendizagem, conteúdos, progressão, avaliação e as finalidades do ensino de História estão intimamente conectadas. O trabalho de Freitas, portanto, mapeia essas questões centrais constituindo-se num roteiro de pesquisa e atuação para quem pensa, ainda, que o ensino de História tem algo a contribuir para a formação do sujeito e da sociedade contemporânea.

NOTA

${ }^{1}$ Disponível em: http://itamarfo.blogspot.com.br/p/sobre-o-blog.html

Resenha recebida em 19 de junho de 2015. Aprovada em 19 de julho de 2015. 